\title{
TIERRAS, TERRITORIOS Y PROCESOS TERRITORIALES: Planteamientos teóricos y análisis de los procesos de acaparamiento de tierras y territorios en Ecuador con posterioridad al 2008
}

\author{
LANDS, TERRITORIES AND TERRITORIAL PROCESSES: \\ Theoretical proposals and analysis of the processes of land hoarding \\ and territories in Ecuador after the 2008
}

Natalia Landívar

FIAN - FoodFirst Information \& Action Network/ Equador natilandi@gmail.com

Luis Llambí

Centro de Antropología/ Instituto Venezolano de Investigaciones Científicas luis.1lambi@gmail.com

\begin{abstract}
Resumen
A inicios del siglo XXI, un nuevo conjunto de procesos de transformación de los territorios, rurales que involucran tanto a viejos como a nuevos actores, están teniendo lugar en el continente como resultado de la re-localización del capital a nivel global. Este artículo analiza procesos territoriales en las tres macro-regiones (Costa, Sierra y Amazonía) en Ecuador, relacionada con el acaparamiento de recursos naturales. Se busca identificar a los principales actores, sus estrategias y vínculos con los macro-procesos estructurales actualmente en curso en el país, las relaciones de poder existentes y las dinámicas de acaparamiento de territorios y los recursos que en ellos se encuentran. Asimismo, el trabajo busca analizar los vínculos entre los diferentes procesos de acaparamiento territorial con los conflictos y luchas de los movimientos sociales vinculados a diferentes tipos de actores territoriales que promueven formas de gobernanza territorial. El principal objetivo del artículo es avanzar hacia la elaboración de un marco conceptual capaz de identificar los diferentes procesos de acaparamiento de los territorios, vincularlos a sus causas y diferenciando las relaciones entre la diversidad de actores en los territorio y plantear algunas hipótesis sobre los procesos de acaparamiento territoriales; y, en particular, con los principales procesos 'neo-extractivistas' actualmente en curso y el papel del Estado.
\end{abstract}

Palabras clave: Tierra. Territorios. Acaparamiento. Ecuador. Recursos naturales. Neoextractivismo.

\section{Abstract}

At the beginning of the XXI century, a new set of processes of transformation of rural territories, involving to both old and new actors, take place in on the continent as a result of the relocation of capital globally. This article analyzes territorial processes in the three

CAMPO-TERRITÓRIO: revista de geografia agrária. Edição especial, p. 76-115, jun., 2016 
Tierras, territorios y procesos territoriales: Planteamientos teóricos y análisis de los procesos de acaparamiento de tierras y territorios en Ecuador con posterioridad al 2008

macro-regions (Costa, Sierra and Amazon) in Ecuador, related with the hoarding of the natural resources. It seeks to identify the key players, their strategies and links with structural macro-processes currently underway in the country, the existing power relations and the dynamics of hoarding of territories and resources that found there. So, this article seeks to analyze the links between the different processes of land grabbing with the conflicts and struggles of social movements linked to different types of territorial actors promoting forms of territorial governance. Also, the main objective of this article is to move towards the development of a theorical-conceptual framework to identify the different processes grabbing territories, linking them to their causes and differentiating the relationships between the diversity of actors in the territory and raise some hypotheses about the processes land grabbing and, in particular, to the neo-extractivist processes currently underway and the role of the state.

Keywords: Land. Territories. Hoarding. Ecuador. Natural resources. Neo-extractivism

\section{Introducción}

Las disputas por el control de la tierra y los recursos naturales han sido una constante en la historia de América Latina. A inicios del siglo XXI, sin embargo, un nuevo conjunto de procesos de transformación de los territorios rurales, que involucran tanto a viejos como a nuevos actores, están teniendo lugar en el continente como resultado de la realocación del capital a nivel global. Estas nuevas dinámicas han reavivado viejos y/o abierto nuevos conflictos, aunque también alianzas entre los diversos actores en juego, cuyas implicaciones para el diseño e implementación de las políticas territoriales a escala subnacional es necesario analizar.

A diferencia de 'la cuestión agraria' que caracterizó a los siglos precedentes, cuando los conflictos por la tierra básicamente se centraron en las relaciones entre hacendados versus 'campesinos sin tierra' (los trabajadores agrícolas) y 'campesinos' (los pequeños productores rurales), los procesos territoriales del siglo XXI tienen dos ejes centrales. Por una parte, las complejas relaciones entre una diversidad de agentes vinculados a la agricultura y al agronegocio, que pudiéramos denominar 'la cuestión agraria' del siglo XXI. Por otra parte, los procesos que involucran a poblaciones que disponen de derechos de propiedad y uso sobre 'territorios' (entiéndase suelos, aguas, bosques y espacio aéreo, y no solo su superficie) que enfrentan los intentos de acaparamiento de los recursos naturales allí

CAMPO-TERRITÓRIO: revista de geografia agrária. Edição especial, p. 76-115, jun., 2016 
existentes por agentes económicos que buscan extraerlos con fines especulativos o de acumulación de capital. Procesos estos últimos que han dado origen a la literatura sobre el 'acaparamiento' de territorios y no solo de 'la tierra', entendida únicamente como el suelo. Ambos procesos frecuentemente cuentan con la activa participación (explícita o implícita) de los Estados nacionales en asociación con agentes económicos que buscan no solo el control (poder) de los territorios por diferentes vías, sino también la consolidación de su participación en los mercados. Esta diversificación de los procesos territoriales plantea, por lo tanto, la necesidad de problematizar en la literatura académica las 'cuestiones territoriales' del siglo XXI, no solo en América Latina, sino a nivel global.

El eje de acumulación identificado como 'extractivismo' también tiene una larga historia en América Latina. Por el contrario, los recientes procesos de acaparamiento de territorios que involucran a poblaciones que disponen de derechos de propiedad, frecuentemente consuetudinarios (es decir, no formalizados legalmente), sobre los recursos y servicios del ambiente biofísico (la 'naturaleza') debido a la expansión de las actividades de empresas mineras, de hidrocarburos, forestales, del agronegocio, etc., en ocasiones con el apoyo explícito de los Estados nacionales, han sido denominados en la literatura como 'neo-extractivismo'.

Con el objetivo de dar una respuesta estratégica a las nuevas demandas del sistema mundial, el gobierno ecuatoriano se ha embarcado en la construcción de un nuevo régimen de acumulación, que pretende, al menos en el discurso, superar el modelo primarioexportador extractivista aplicado en el pasado. Esto ha llevado a que diferentes procesos territoriales estén en marcha redefiniendo las actividades productivas extractivas tradicionales en las diferentes macro-regiones del Ecuador.

Este artículo toma como referencia empírica la incipiente información e investigación realizada sobre específicos procesos territoriales en las tres macro-regiones (Costa, Sierra y Amazonía) en Ecuador, relacionada con el acaparamiento de recursos naturales, estos son, inversiones en la maricultura, la producción de agrocombustibles, la ampliación de la explotación petrólera y su vínculo con la nueva infraestructura petroléra y vial, y la diversificación de la floricultura. Con base en el análisis de cuatro casos en las tres

CAMPO-TERRITÓRIO: revista de geografia agrária. Edição especial, p. 76-115, jun., 2016 
Tierras, territorios y procesos territoriales: Planteamientos teóricos y análisis de los procesos de acaparamiento de tierras

diferentes macro-regiones se busca identificar a los principales actores, sus estrategias y vínculos con los macro-procesos estructurales actualmente en curso en el país, las relaciones de poder existentes, así como las dinámicas y los mecanismos acaparamiento de territorios y los recursos que en ellos se encuentran. Por último, pero no menos importante, el trabajo busca analizar los vínculos entre los diferentes procesos de acaparamiento territorial con los conflictos y luchas de los movimientos sociales vinculados a diferentes tipos de actores territoriales que promueven formas de gobernanza territorial alternativas.

Estos procesos, como se verá más adelante, no abordan aspectos meramente agrarios. Lo que, esperamos, nos permitirá superar la antigua visión agrarista, en gran medida enfocada hacia el análisis de los procesos agronómicos, aún predominante en la literatura. Si bien importante, este enfoque se queda corto a la hora de describir la problemática actual del acaparamiento de tierras de manera holística. El análisis comparativo de estos procesos busca también contribuir a cuestionar el planteamiento de que en Ecuador no existen procesos de acaparamiento vinculados a las dinámicas globales generadas por las múltiples crisis actualmente en curso.

El principal objetivo del artículo, por lo tanto, es avanzar hacia la elaboración de un marco conceptual que nos permita la gradual construcción de una teoría capaz de identificar los diferentes procesos de acaparamiento de los territorios, vincularlos a sus causas (p.ej. sus vínculos o no con las grandes empresas, los capitales regionales y transnacionales, los mercados nacionales e internacionales y las transformaciones geopolíticas globales), diferenciando las relaciones entre la diversidad de actores en los territorio; para, a partir de ahí, plantear algunas hipótesis sobre los procesos de acaparamiento territoriales; y, en particular, con los principales procesos 'neo-extractivistas' actualmente en curso. Especial énfasis otorga también el artículo al análisis del papel asumido por el Estado, y su importancia en la concepción de políticas públicas, particularmente a nivel subnacional, coherentes con las reformas planteadas por la Asamblea Constituyente de 2007-2008. 
Tierras, territorios y procesos territoriales: Planteamientos teóricos y análisis de los procesos de acaparamiento de tierras y territorios en Ecuador con posterioridad al 2008

\section{Propuestas teóricas para el análisis de los procesos territoriales}

\section{Acaparamiento de tierras, territorios y procesos territoriales}

La perspectiva territorial adoptada en este documento apunta a la necesidad de analizar las estrategias de los actores sociales, enmarcados en procesos territoriales subnacionales, y de sus relaciones con otros actores con los cuales entran en diferentes tipos de relaciones (p.ej. de conflicto y/o de cooperación).

No obstante, el enfoque adoptado plantea que la adopción de una perspectiva exclusivamente territorial (sub-nacional) sería insuficiente a fin de entender los procesos de acaparamiento que se busca analizar. El estudio de Borras et. al (2012) sobre la economía política de los procesos de acaparamientos en América Latina sugiere que la acumulación del capital financiero internacional suele ser un actor central que busca concluir alianzas tanto con las empresas domésticas y/o regionales como con los Estados nacionales. Proponemos, por lo tanto, retomar y ampliar los elementos que Borras et. al (2012) proponen para el análisis, con base en las siguientes preguntas: ¿quién controla no solo la tierra (entendida como el suelo y sus recursos), sino el territorio (definido socialmente), y los recursos a ellos asociados?; ¿qué relaciones de poder subyacen a esos procesos?; y, por último, ¿qué diferencias es posible identificar entre los procesos de acaparamiento vinculados a la producción de alimentos versus los vinculados a las actividades extractivas, que se dan en respuesta a los procesos de reajuste del capital en el marco de las múltiples crisis internacionales y/o de la incorporación de nuevos centros de capital a los escenarios globales?

Por otra parte, el enfoque adoptado plantea superar el concepto de 'acaparamiento de tierra' (land-grabbing en inglés), que consideramos sumamente restrictivo por el de acaparamiento territorial, lo que incluye no solo los recursos vinculados al suelo sino también al subsuelo. Para esto consideramos útil retomar la noción de territorio propuesta por Haesbaert (2008) para entender mejor los procesos neo-extractivistas analizados en el documento:

"Se relaciona al poder, pero no solamente el tradicional poder político

(...) sino poder tanto en el sentido más concreto de dominación, como al

CAMPO-TERRITÓRIO: revista de geografia agrária. Edição especial, p. 76-115, jun., 2016 
más simbólico de apropiación (cfr. Lefebvre 1974) (...). Pudiéramos, por lo tanto, afirmar que el territorio, inmerso en relaciones de dominación y/o de apropiación sociedad-espacio, se desdobla a lo largo de un continuum que va de la dominación político-económica (o 'concreta') y de la apropiación subjetiva ('cultural' o 'simbólica')" (Haesbaert 2008 en Bonilla et al. 2015, parafraseado).

Lo que supone considerar no solo la apropiación del suelo, sino también del sub-suelo e, incluso, del espacio aéreo territorial. Un aspecto adicional del enfoque de acaparamiento territorial propuesto es que permite analizar los procesos de destrucción de los valores culturales y espirituales que suelen estar asociados a los actuales procesos de aparamiento, entendidos como mecanismo de dominación. Y, por lo tanto, dependiendo de los diferentes procesos de acaparamiento territorial que analizamos, permite considerar sus vínculos tanto con los valores culturales y espirituales de las poblaciones territoriales, como con sus impactos directos e indirectos sobre los ecosistemas a los que los territorios están vinculados.

La búsqueda de un hilo conductor coherente entre los 'macro-procesos' estructurales y los 'micro-procesos' territoriales supone, por lo tanto, de la elaboración de una matriz conceptual capaz de explicitar las posibles relaciones causales entre los diversos componentes: económico-políticos, culturales, y ambientales.

\section{Las nociones de 'tierra' $y$ 'territorio'}

Desde la perspectiva de los actores locales, los territorios son construcciones sociales. Es decir, son espacios socialmente delimitados que resultan de los procesos a través de los cuales los actores organizan, demarcan y se apropian de hábitats naturales a fin de lograr sus fines individuales y/o colectivos. En otras palabras, los territorios no existen por sí mismos, sino que son construídos socialmente tanto por las historias locales, como por los macro-procesos históricos en los que están insertos; así como por las formas en que las poblaciones trabajan, negocian y dan sentido a estos procesos. En este sentido, muchos conflictos entre los actores que influyen en un territorio están dados por la construcción del espacio, es decir, sobre el tipo de relaciones entre la sociedad y la naturaleza que predominan en el territorio y sobre las estructuras de poder (a diferentes escalas espaciales) en las que están insertos.

CAMPO-TERRITÓRIO: revista de geografia agrária. Edição especial, p. 76-115, jun., 2016 
En otras palabras, los territorios no existen externamente a la conceptualización que de ellos hacen los actores locales, sino que resultan tanto de las historias individuales y colectivas de los actores, como de las formas como ellos/ellas le dan sentido a estos procesos. Por el contrario, desde la perspectiva de los actores externos al territorio (p.ej. las entidades estatales y para-estatales, las ONGs, las agencias internacionales, etc.), los territorios son ámbitos geográficos determinados por las categorías administrativas con base a las cuales esos actores definen sus formas de intervención (p.ej., las políticas públicas y/o los programas y proyectos de inversión de los diferentes agentes externos).

Una tendencia reciente a escala global es la redefinición de los territorios subnacionales, a veces como resultado de la fusión de anteriores jurisdicciones políticas, y otras como resultado de entidades creadas ad hoc por organizaciones de la sociedad civil. El resultado final de estos procesos es que las entidades territoriales sub-nacionales son definidas formalmente (p.ej., administrativamente) desde arriba; o, informalmente, por acuerdos colectivos desde abajo (Llambi, 2010).

\section{Extractivismo, acaparamiento de territorios y políticas públicas}

Como mencionamos al inicio, en el contexto actual de América Latina, algunos de los principales procesos de acaparamiento están vinculados a actividades extractivas, muchas de las cuales tienen efectos no solo sobre los componentes agrícolas del territorio, sino también sobre los no-agrícola (p.ej. forestales, mineros, hidrocarburíferos, etc.).

Disponemos ya de una amplia literatura sobre el extractivismo. En particular, el concepto de 'neo-extractivismo', elaborado por Gudynas, tiene el mérito de plantear una clara diferenciación entre los procesos extractivistas de las décadas de los 80 y 90, en los cuales el Estado asumía un papel principalmente facilitador, con los actuales procesos vinculados al conjunto de políticas públicas implementadas por algunos gobiernos que se auto-denominan 'progresistas', pero que en la práctica también facilitan los procesos de acumulación de capital en detrimento de los intereses de las poblaciones territoriales. Según Gudynas, este 'neo-extractivismo' también tiende a fragmentar el territorio, en la medida 
Tierras, territorios y procesos territoriales: Planteamientos teóricos y análisis de los procesos de acaparamiento de tierras y territorios en Ecuador con posterioridad al 2008

que no solo reconfigura su espacio físico, sino también las relaciones sociales de los actores involucrados (Gudynas, 2009: 201-202).

\section{Estructuras de poder, Estados, políticas públicas e instituciones de gobernanza}

Las estructuras de poder en la medida que influyen en las estrategias de vida de los actores sociales, son centrales en el enfoque institucionalista. El poder, por lo tanto, no es sólo un contexto sino un importante componente analítico de la agenda de investigación. Una categoría teórica que incluye no solo a los Estados y sus estructuras institucionales a diferentes niveles, sino también la influencia de los capitales privados y de las relaciones de mercado.

\section{Naturaleza, ambiente biofísico y sus vínculos con los procesos territoriales}

A escala global, existen múltiples evidencias de los efectos del actual cambio climático sobre otros procesos biofísicos como la desertificación y la extinción de especies, lo que genera múltiples consecuencias sobre las poblaciones humanas vinculadas a los territorios rurales. A escala nacional y sub-nacional se han identificado estrechas relaciones entre otros procesos biofísicos (p.ej.. fenómenos sísmicos, cambios en la dinámica de los océanos, etc.) y sus impactos en los procesos territoriales. También, en sentido contrario, la literatura académica, y principalmente la que proviene de la ecología política, ha identificado relaciones causales entre procesos sociales a diferentes escalas (p.ej. cambios tecnológicos, fluctuaciones de precios, transformaciones de las infraestructuras físicas, etc.) y sus efectos en la transformación de los entornos biofísicos. Lo que a su vez genera problemas sociales como el deterioro de la base de recursos de las poblaciones tanto rurales como urbanas, o los efectos que la adopción de tecnologías intensivas en capital para la producción agrícola genera en el deterioro de los ecosistemas (naturales y manejados), o los múltiples vínculos entre las crisis ambientales y el deterioro de la salud y de la alimentación de las poblaciones rurales.

El estrecho vínculo entre los territorios y su contexto biofísico también requiere del análisis de los múltiples dilemas que pueden surgir en los mecanismos de gestión de los

CAMPO-TERRITÓRIO: revista de geografia agrária. Edição especial, p. 76-115, jun., 2016 
Tierras, territorios y procesos territoriales: Planteamientos teóricos y análisis de los procesos de acaparamiento de tierras

ecosistemas (naturales y manejados), y de los objetivos de los actores sociales (públicos y privados).

\section{El potencial empoderamiento de las organizaciones de la sociedad civil}

En América Latina, durante las dos últimas décadas, diversos tipos de organizaciones de la sociedad civil y de los movimientos sociales han emergido en un gran número de países como importantes actores en la reestructuración de las instituciones de gobernanza (económica, social y ambiental), a diferentes escalas territoriales, debido a su creciente participación en los debates para modificar las reglas de juego que afectan a los territorios. Lo importante a destacar aquí es que, en épocas recientes, los movimientos sociales, acompañados o no por organizaciones no gubernamentales (ONGs), o de la cooperación internacional, frecuentemente han sido capaces de participar en el diseño y la implementación de las políticas públicas territoriales a diferentes escalas.

Por otra parte, la expansión masiva de las voces políticas y el activismo social en relación a las décadas pasadas, con un crecimiento acelerado de las demandas por transparencia y rendición de cuentas, y la erupción de movimientos de protesta en diversos países ha generado grandes expectativas sobre el potencial de transformación de la participación política a escala territorial sub-nacional. El supuesto es que, cuando las poblaciones locales participan en los procesos de transformación económica y están bien informadas, tienden a demandar la rendición de cuentas en los temas que les concierne; lo que, en última instancia, puede incrementar la calidad de la gobernanza y sus resultados. Las luchas por una mayor inclusión social, el monitoreo de las políticas, la rendición de cuentas y la representatividad social en el diseño de los proyectos, es un proceso de luchas y negociaciones, pero sobre todo de modificación de las relaciones de poder.

El empoderamiento es un proceso mediante el cual los actores individuales y colectivos acceden a recursos y toman control de sus propias vidas. Cuando las poblaciones territoriales participan en los procesos de transformación económica y están bien informadas, tienden a demandar una efectiva rendición de cuentas en los temas que les concierne; lo que, en última instancia, puede incrementar la calidad de la gobernanza, el

CAMPO-TERRITÓRIO: revista de geografia agrária. Edição especial, p. 76-115, jun., 2016 
monitoreo de las políticas, y sus resultados. Las luchas por una mayor inclusión social, la rendición de cuentas y la representatividad son, sin embargo, resultado de procesos de luchas y de negociaciones, cuyos resultados en última instancia dependen de la efectiva modificación de las relaciones de poder. Muchos iniciales procesos de empoderamiento de las organizaciones sociales, sin embargo, concluyen con magros resultados o en fracasos debido a sus conflictos internos, o debido a las dificultades de conformación de alianzas entre las organizaciones sociales o sus líderes, lo que tiende a erosionar su capacidad para impulsar sus propuestas de transformación.

Pero la movilización ciudadana a través de organizaciones aisladas no es suficiente: las redes sociales son esenciales para el logro de los objetivos planteados por las organizaciones territoriales. También es necesario garantizar, a través de las movilizaciones sociales, que los gobiernos respondan a las necesidades y demandas de los ciudadanos. Lo que es indispensable a fin de darle contenido real al empoderamiento y avanzar más allá de los slogans políticos (Rocha Menocal 2015, parafraseado).

\section{Ecuador: procesos territoriales rurales en el marco del "nuevo" régimen de acumulación del capital}

\section{Antecedentes}

El gobierno ecuatoriano ha apostado hacia la construcción de un régimen de acumulación centrado en el desarrollo endógeno con vinculación estratégica al sistema mundial a través de una propuesta de transformación de la matriz productiva (SENPLADES, 2012: 9). Esta nueva matriz productiva se constituyó en el eje central del programa de la gestión del gobierno del movimiento Alianza País para el período 20132017. El objetivo central que planteaba esta propuesta era pasar de una matriz especializada en el sector primario exportador - extractivista a otra que privilegie la producción diversificada con mayor valor agregado basada en el conocimiento y capacidades de la población y la eco-eficiencia. En la propuesta inicial de la Secretaría Nacional de Planificación y Desarrollo (SENPLADES) en el año 2012, se incluyeron cuatro ejes centrales: i) el desarrollo de industrias estratégicas (refinería, astillero, petroquímica, 
metalurgia y siderúrgica) y nuevas actividades productivas (maricultura, biocombustibles y productos forestales); ii) la agregación de valor a los bio-emprendimientos (bioquímica y biomedicina), servicios ambientales y energías renovables; iii) la sustitución selectiva de importaciones de bienes y servicios (farmacéutica, tecnología y metalmecánica); y iv) el fomento a la exportación de nuevos productos provenientes de actores ligados a la economía popular y solidaria o con mayor valor agregado (alimentos frescos y procesados, turismo, etc.) (SENPLADES, 2012).

Desde el año 2010, el gobierno ha estado construyendo la normativa e infraestructura que estimaron necesaria para el cambio de la matriz productiva (SENPLADES, 2012: 13). Entre los instrumentos normativos más importantes para promover el cambio de la matriz productiva cabe mencionar la Agenda de Transformación Productiva (ATP) de 2010-2013 y el Código Orgánico de la Producción, Comercio e Inversiones (COPCI) del año 2010․ Sus objetivos eran generar tanto seguridad jurídica como incentivos fiscales para la inversión privada en sectores estratégicos; conjuntamente con la cooperación público-privada para el desarrollo productivo (cfr. Consejo Sectorial de la Producción, 2010: 18 y 19). Otros mecanismos son: i) la actualización del Plan Nacional de Buen Vivir 2013-2017, que en su objetivo 10 incluye políticas, lineamientos estratégicos y metas para la conformación de nuevos sectores e industrias con alta productividad y competitividad; y ii) la Ley Orgánica de Regulación y Control del Poder de Mercado, que busca establecer las principales reglas de juego para los actores económicos. El Presidente de la República también decretó en el año 2013 el Comité Interinstitucional para el Cambio de la Matriz Productiva ${ }^{2}$, presidido por el Vicepresidente $^{3}$. A fin de articular tanto los componentes sociales como ambientales a los procesos de transformación de la matriz productiva, en el 2014 la SENPLADES diseñó la Estrategia Nacional para la Igualdad y la Erradicación de la Pobreza (ENIEP), no obstante más allá de proporcionar lineamientos generales, no llegó a identificar los mecanismos necesarios para implementarlos en políticas, planes, y programas. Por último, en el período 2010-2015, el Estado ha realizado fuertes inversiones de capital en el desarrollo de elementos tanto de la infraestructura material y humana (p.ej. vinculados a la educación, el desarrollo 
Tierras, territorios y procesos territoriales: Planteamientos teóricos y análisis de los procesos de acaparamiento de tierras y territorios en Ecuador con posterioridad al 2008

científico, las telecomunicaciones), como de la vialidad y las fuentes de energía renovable para la transformación de la matriz productiva.

\section{Actividades extractivas históricas y contemporáneas por regiones geográficas}

\section{La región de la Costa}

En la Costa, el proceso fundamental fue la consolidación de una burguesía mercantil, cuyo centro principal geográfico fue la ciudad de Guayaquil, sede de los principales intercambios comerciales con la metrópolis española. Desde el siglo XVII hasta inicios del siglo XVIII, las principales exportaciones del país eran de productos serranos, seguidas de las exportaciones agrícolas del litoral, con base en grandes propiedades caracterizadas inicialmente por el trabajo esclavo; y, posteriormente por el trabajo asalariado. Durante todo este período, la Costa fue una de las regiones donde más se transformó la naturaleza a fin de sostener actividades como los astilleros del río Guayas.

A mediados del siglo XIX, inicios del desarrollo capitalista, poderosos grupos minoritarios de agroexportadores terratenientes dominaron el mercado de exportación de cacao. El poder de la coalición de clases "burguesa-terateniente" ligados al sector agroexportador en alianza con los gobiernos nacionales y el capital transnacional se consolidó durante el boom bananero (1948-1964) del siglo XX. Una injusta y desigual estructura agraria se consolidó con las políticas neoliberales de los años noventa dirigidas a la producción agrícola a gran escala en manos de la clase terrateniente agro-exportadora. Para el nuevo siglo, se expandió la producción de bienes primarios no tradicionales agroindustriales, como palma africana y caña de azúcar, mientras los productos tradicionales de exportación como banano, café y cacao, crecieron moderadamente (Larrea, 2008: 132).

\section{La actividad camaronera y el nuevo sector productivo de la maricultura}

En la Costa, la cría de camarón en piscina comenzó a desarrollarse en los años sesenta y, para finales de la década de 1990, gracias a sus ventajas comparativas, llegó a ocupar el segundo lugar de todas las exportaciones después del petróleo (Góngora y Benavides, 2007: 25-26). En esa década, desde el sector estatal y académico ${ }^{4}$, como también del sector privado, 
comenzó a generarse la institucionalidad necesaria para el crecimiento de esta rama productiva considerada como estratégica. Para los años noventa se concedieron beneficios directos e indirectos para el sector privado, ${ }^{5}$ que apuntaban a generar las condiciones financieras y de seguridad jurídica necesarias para garantizar la inversión privada en el sector camaronero (Góngora y Benavides, 2007: 28). En los últimos cuatro años, como consecuencia de la apertura de nuevos mercados en algunos países asiáticos ${ }^{6}$, el mapa exportador camaronero del Ecuador se ha venido modificando. Las exportaciones de este producto a Asia pasaron de un 2\% en 2010 a 30\% en 2014, convirtiendo a esta región en el segundo mercado del camarón ecuatoriano (Revista Acuacultura, 2015: 12). El incipiente auge de las exportaciones camaroneras a esta región motivaron al gobierno a apostar fuertemente por la maricultura ${ }^{7}$ como nueva cadena productiva.

Con base en el eslogan "el futuro está en el mar", el gobierno comenzó a otorgar concesiones a mar abierto, líneas de crédito especializadas y asistencia técnica gratuita tanto a los pescadores artesanales como a la empresa privada (Expreso, Marzo 3 de 2014). De hecho, el Viceministerio de Acuacultura y Pesca (2015), entregó recientemente una concesión de 86,70 hectáreas y créditos blandos a bajo interés a una empresa privada para la primera siembra experimental de peces en cautiverio a nueve millas de la costa de Jaramijó, en la provincia de Manabí. Desde 2014, para la producción de camarón se están financiando siete proyectos experimentales de cultivo en el mar del marisco dirigido a pescadores artesanales (Diario Expreso, Mayo 10 de 2015), del cual aún no conocemos sus resultados. Si bien no existe información oficial al respecto, se evidencia, no obstante, un inminente peligro de acaparamiento de los recursos marinos en el futuro cercano, dado por la existencia de actividades desreguladas de maricultura en manos de empresarios privados con grandes capitales ligados a pesca industrial (Entrevista a Líder Góngora y Marianelli Benavides, Julio 3 de 2015).

Si bien la maricultura ha sido presentada como medio a fin de evitar la ampliación de la frontera camaronera en los bosques remanentes de manglar, y evitar así su deterioro, aún son necesarias las piscinas camaroneras en tierra para la cría de las larvas. En los últimos cuarenta años, estas piscinas se asentaron en las áreas del ecosistema manglar ${ }^{8}$. De

CAMPO-TERRITÓRIO: revista de geografia agrária. Edição especial, p. 76-115, jun., 2016 
Tierras, territorios y procesos territoriales: Planteamientos teóricos y análisis de los procesos de acaparamiento de tierras y territorios en Ecuador con posterioridad al 2008

acuerdo al CLIRSEN (2007) , entre 1969 y 1999, el área del manglar se redujo de 202.201 hectáreas a 148.230 hectáreas, lo que significa una reducción del 30\%, atribuible principalmente a la actividad camaronera, según un estudio de Banco Mundial (Marriot, 2003: 39) ${ }^{10}$. Diferentes instrumentos legales desde 1960 resultaron "letra muerta" para proteger al ecosistema del manglar, ${ }^{11}$ y las normas básicas para su uso a través de concesiones por un lapso de 10 años no fueron respetadas, ${ }^{12}$ mientras que las entidades e instituciones encargadas de protegerlo actuaron de manera descoordinada (Góngora y Benavides, 2007: 107-112) ${ }^{13}$.

Por otra parte, aunque la posibilidad de inserción en la nueva dinámica de producción de camarón a mar abierto aún no pareciera atractiva para el sector privado, ya que aparentemente no confían en su rentabilidad, sí lo es el incremento de la demanda de los mariscos y la posibilidad de incrementar las exportaciones hacia nuevos mercados mediante, inclusive, nuevas inversiones extranjeras en el país (Entrevista a Ing. Yahira Piedrahita, junio 1 de 2015). Por esto, el sector privado organizado en la Cámara Nacional de Acuacultura (CNA) ${ }^{14}$ ha apostado por beneficiarse de las políticas públicas dirigidas a los procesos macro económicos en marcha. Un aspecto importante ha sido la ampliación del período de concesión a la actividad camaronera. Como resultado de este lobby, en octubre del año 2008 se sancionó el Decreto Ejecutivo 1391, con el cual se comenzó a impulsar la regularización para productores camaroneros en áreas de playas y bahías que habían ocupado un área mayor a la concedida, o que no disponían de concesión, o que habían recibido adjudicaciones por el entonces Instituto Nacional de Reforma Agraria y Colonización (posteriormente Instituto Nacional de Desarrollo Agrario (Art. 1) ${ }^{15}{ }^{16}$. En 2009 , este decreto fue reforzado con la emisión de la LORSA ${ }^{17}$.

En realidad, estas medidas solo estaban dirigidas a un segmento de las camaroneros artesanales con extensiones menores a 30 hectáreas que se habían ubicado en zonas de playa y bahías sin documentación en regla (Revista Acuacultura, 2012: 6); y dejaron intactos los intereses de los grandes propietarios, quienes, según datos de la CNA y la Subsecretaría de Acuacultura, ya disponían de permisos y/o acuerdos de operación. Se trata del 3\% del total de camaroneras, con más de 250 has. que concentran 46154 has. (24\% del

CAMPO-TERRITÓRIO: revista de geografia agrária. Edição especial, p. 76-115, jun., 2016 
total de has.), localizados en llamadas zonas altas y sin vocación agrícola, y 30\% del total de camaroneras, con entre 50 y 250 has. que abarcan unas 105603 has., (55\% del total de has.), ubicadas en zona de bahía y playa y zonas altas. De acuerdo a la C-CONDEM, la denominación de zonas altas y sin vocación agrícola a grandes extensiones ocultó la tala indiscriminada e ilegal en zona de manglar, por lo que estos intrumentos legales terminaron facilitando la adjudicación de las zonas de manglar que fueron consecionadas en las últimas décadas (Entrevista a Líder Góngora y Marianelli Benavides, Julio 3 de 2015).

Existen intereses antagónicos entre las organizaciones sociales asociados a los recursos marinos y zonas de manglar. Por un lado, organizaciones como la Federación Nacional de Cooperativas Pesqueras Artesanales del Ecuador (FENACOPEC) han establecido alianzas con el gobierno nacional y son beneficiarias directas del proyecto de siembra de camarón en el mar (Diario Expreso, Junio 17 de 2014) o de la adjudicación de camaroneras incautadas a grupos banqueros a través de la política nacional de redistribución de tierra (El Universo, abril 22 de 2015). Por otra parte, la movilización social encausada por organizaciones como la Coordinadora Nacional para la Defensa del Ecosistema del Manglar (C-CONDEM), que representan los intereses de usuarios del manglar, se contrapone directamente con las propuestas del Estado. Su lucha por la conservación del ecosistema manglar y modelos participativos y comunitarios de autogestión ha tenido como consecuencia la sanción de varios instrumentos que promueven otro modelo, p.ej. el Decreto Ejecutivo 1102 de julio de $1999^{18}$, el cual posibilitaba el manejo colectivo de las áreas del ecosistema de manglar mediante la figura de acuerdos de uso sustentable y custodia por diez años ${ }^{19}$, o el Acuerdo Ministerial 156 del año 2014, por medio de cual se estableció el reconocimiento de las áreas protegidas comunitarias y las normas para su incorporación al Sistema Nacional de áreas Protegidas (SNAP) ${ }^{20}$.

Lo importante a destacar aquí es que estos procesos han contribuido al debilitamiento y la desarticulación de las organizaciones de base a través de diferentes mecanismos implementados por el Estado, p.ej. la entrega de bonos, programas de alimentos, la contratación de promotores, que a su vez son miembros de las organizaciones, la participación en las 
actividades de reforestación de las camaroneras, y la cooptación de las organizaciones de base mediante nuevas figuras organizativas incentivadas por el gobierno nacional.

\section{Caña de azúcar y biocombustibles}

La producción de caña de azúcar ha estado dirigida a la elaboración de azúcar, y de manera secundaria, de panela y alcohol ${ }^{21}$. Tres ingenios han absorbido históricamente el 90\% de la producción azucarera: San Carlos y Valdez desde finales del siglo XIX, y Ecudos (antiguo Aztra) desde mediados del siglo XX ${ }^{22}$. En la década de 1960, el cultivo de caña de azúcar comenzó a cobrar más importancia gracias a mejoramientos en la producción y en los rendimientos por hectárea (Cueva García, 2001: 8). Factores que ubicaron muy pronto al cultivo de caña de azúcar entre las tres explotaciones agrarias mayores del país (INEC, 2013).

El cultivo de caña de azúcar para la producción de etanol es una actividad reciente en el país ${ }^{23}$. Pese a que en el año 2004 la producción de agrocombustibles se había declarado de interés nacional mediante el Decreto Ejecutivo No. 2332, es en el actual período de gobierno que el sector comienza a desarrollarse con mayor fuerza como resultado de la política de cambio en la matriz productiva y energética que promueve el gobierno nacional ${ }^{24}$. Desde el año 2013 se ejecuta el Programa Nacional Agroenergía, dirigido a incrementar la producción de materias primas agrícolas para la producción de energía renovables, con base en la generación de alternativas de producción agrícola campesina. Esta propuesta se enmarca dentro del Plan Nacional del Buen Vivir 2009-2013, y contempla el financiamiento de los costos de producción durante el primer año de implementación de los canteros y de los semilleros de la caña (MAGAP, 2014). Además, se trata de un programa complementario al plan piloto de producción de etanol denominado Eco-País ${ }^{25}$ que desde 2010 comercializa gasolina extra con 5\% de etanol anhíbrido en la ciudad de Guayaquil.

La agencias públicas vinculadas a este programa dicen identificar la soberanía alimentaria, la sostenibilidad ambiental y el desarrollo agroindustrial como los ejes centrales de su discurso para promover la producción de agrocombustibles. Argumentan, en

CAMPO-TERRITÓRIO: revista de geografia agrária. Edição especial, p. 76-115, jun., 2016 
Tierras, territorios y procesos territoriales: Planteamientos teóricos y análisis de los procesos de acaparamiento de tierras

primer lugar, que la reducción de emisiones de dióxido de carbono $(\mathrm{CO} 2)$ conlleva no solo un decrecimiento de la contaminación ambiental, sino también un importante ahorro económico para el Estado. En segundo lugar, afirman que el programa fomenta la generación de empleos a través de la inclusión productiva de los agricultores a la agroindustria de la caña de azúcar con la cobertura del 39\% de los costos de producción y la garantía de la comercialización de las semillas (El Telégrafo, octubre, 2013). En tercer lugar, enfatizan que la producción de azúcar no se vería afectada, debido a que la ampliación de cultivos se daría en predios baldíos.

No obstante, es ampliamente conocido el efecto de concentración de tierra causado por la producción de caña de azúcar. De acuerdo al III Censo Agropecuario del 2000, la estructura de la propiedad de la tierra estaba concentrada en manos de grandes propietarios (el 4\% de las unidades de producción con propiedades mayores a 200 has.), que abarcaban el $75 \%$ del total de las hectáreas destinadas a la producción de caña de azúcar. El estudio del SIPAE, que usó los datos del último censo agrario del año 2000, señala que los cantones de influencia de los principales ingenios registraron los niveles más altos de concentración de tierra ${ }^{26}$. Estos datos evidencian que el incremento de la superficie de cañicultura estaba directamente relacionado con la concentración de la superficie agrícola disponible por parte de los ingenios azucareros (Martínez Valle, 2012 y SIPAE 2010). Datos más actuales dan cuenta que en 2013 existía una superficie de 113160 has. concentrada mayormente en la provincia del Guayas donde se producen más de 6 millones de toneladas de azúcar (INEC, 2013). Por lo demás, se prevé un incremento anual de 10 mil hectáreas hasta llegar a 83 mil hectáreas en el 2020 para alcanzar la meta de 800 millones de litros de etanol anhíbrido para el año 2020 con una fórmula del 15\% de etanol anhíbrido en la gasolina extra (El Telégrafo, diciembre 2013). Se ha hecho público que el gobierno estaría realizando estudios en varias zonas de la península de Santa Elena y la provincia de Los Ríos con este objetivo (El Telégrafo, octubre 2013).

El Programa Nacional de Agroenergía fue iniciado en el año 2013 en la Hacienda La Indiana de 1400 has., ubicada en el cantón Naranjal, de la provincia del Guayas, propiedad incautada en 2009 al grupo Isaías y transferida en 2011 a cuatro asociaciones de pequeños

CAMPO-TERRITÓRIO: revista de geografia agrária. Edição especial, p. 76-115, jun., 2016 
Tierras, territorios y procesos territoriales: Planteamientos teóricos y análisis de los procesos de acaparamiento de tierras y territorios en Ecuador con posterioridad al 2008

productores ${ }^{27}$ a través del Plan Tierras ${ }^{28}$ con crédito del Banco Nacional de Fomento. En ese sitio el Plan Tierras benefició alrededor de 250 familias pertenecientes a cuatro asociaciones, a las cuales les fue entregado un título en copropiedad. Para garantizar la venta de caña para la producción de azúcar, las asociaciones firmaron un contrato en el 2012 con el ingenio Ecudos por período de cinco años, a través de la figura de agricultura bajo contrato con la cual han accedido a créditos 25.000 dólares por organización. Este predio está considerado como el semillero de caña para la elaboración de agrocombustibles, para lo cual los agricultores asociados estarían destinando la mitad de las hectáreas de la hacienda (MAGAP, octubre 2013). Hasta la fecha, no se ha encontrado información pública sobre los resultados alcanzados por los semilleros, no obstante, se evidencia que el modelo de producción que se practica aquí entra en evidente contradicción con el discurso de la Soberanía Alimentaria que defienden organizaciones campesinas como la Vía Campesina tanto en América Latina como a nivel mundial. De acuerdo a Ericsson (2013), por un lado, en la Hacienda La Indiana existe una gran presión por parte de los funcionarios públicos, que imponen “desde arriba", el modelo agrícola convencional de monocultivos a fin de incrementar la productividad y cumplir con las obligaciones bancarias; y, por otro lado, resignación por parte de las asociaciones de pequeños productores, quienes aceptan este modelo de productivo como respaldo político al gobierno y a su política agraria (Ericsson, 2013: 10-14).

El principal beneficiario del programa Agroenergía es el Grupo Gloria. Este grupo económico es un conglomerado industrial de capital peruano presente en los sectores de la alimentación y lácteos y agroindustria, etc. en diversos países de la región. Actualmente, es el mayor accionista del Ingenio Ecudos, propiedad que le fue transferida (en la mayoría de sus acciones) en 2011 por la entonces Agencia de Garantías de Depósito (AGD) mediante subastas que se realizaron de los bienes incautados al grupo Isaías. Por una parte, el ingenio es el comprador de la producción de caña para la elaboración de azúcar de la Hacienda La Indiana, y por otra parte, es el mayor aportante a la producción de alcohol del proyecto Eco-País (El Telégrafo, diciembre 2013) ${ }^{29}$. Se menciona también que este grupo económico estaría realizando una importante inversión a fin de instalar un complejo industrial para la producción de 180 millones lts. de alcohol (Ministerio Coordinador de Producción, Empleo

CAMPO-TERRITÓRIO: revista de geografia agrária. Edição especial, p. 76-115, jun., 2016 
y Competitividad, 2013). Esta infraestructura estaría ubicada en el proyecto multipropósito Dauvín en la provincia de Los Ríos, a cargo de la Secretaría del Agua y la de empresa constructora Odebrecht (Secretaría del Agua, 2014).

La región de la sierra

En la Sierra - donde se concentra la mayor biodiversidad ecosistémica debido a los diferentes pisos climáticos-los procesos de acaparamiento territorial principalmente se vincularon a la producción agroexportadora, caracterizada por el tradicional sistema de la hacienda. Sistema que, históricamente, se basaba en la servidumbre indígena vinculada a una pequeña élite de grandes propietarios rurales. Este sistema productivo se inició en el período colonial y se prolongó hasta la década de 1960, cuando se llevó a cabo la primera reforma agraria del país que abolió la servidumbre. Hoy en día, especialmente en la sierra centro-norte estos sistemas han sido reemplazados por modernas empresas florícolas o de hortalizas.

\section{Floricultura}

La floricultura en el Ecuador comenzó a desarrollarse en los años noventa como resultado de diferentes medidas financieras y comerciales que se implementaron en esos años, como el Tratado de Preferencias Arancelarias Andinas con los Estados Unidos (conocido como ATPDEA) ${ }^{30}$ y una política general de apertura comercial que incentivó la producción de flores para la exportación. Además de las iniciativas estatales y de mercado, otros factores que influyeron en el auge florícola de los años noventa fueron la relativa estabilidad política y la flexibilización laboral en comparación con otros países como Colombia (Korovkin y Sanmiguel, 2007: 23) ${ }^{31}$. Hoy, este sector está considerado como uno de los motores del comercio exterior; y, el Ecuador, como uno de los países exportadores que ofrece mayor diversidad de flores $^{32}$ a los mercados mundiales. Las rosas y las gyphosofilas han sido las principales flores de exportación en el período 2008-2012, destacándose el crecimiento de la demanda de estas últimas (ProEcuador, 2013) ${ }^{33}$. En el marco del proceso de cambio de la matriz productiva, el sector florícola está considerado como un ejemplo a seguir, por lo que el gobierno se ha comprometido a apoyarlo a través

CAMPO-TERRITÓRIO: revista de geografia agrária. Edição especial, p. 76-115, jun., 2016 
del fomento a la exportación hacia nuevos mercados y del incremento la variedad de ofertas de flores (El Telégrafo, Junio 11 de 2014).

En cuanto a su política de diversificación de los mercados de destino para los productos ecuatorianos, el Ecuador ya ha adelantado convenios con ciertos países en las regiones de Asia, Medio Oriente y la Cuenca del Pacífico. Recientemente, el gobierno ha comenzado a facilitar acuerdos para incrementar la oferta exportable a China, un país que el sector privado considera un mercado por conquistar ${ }^{34}$. En el período 2001 al 2014 las exportaciones de flores ecuatorianas a China se incrementaron en $232 \%$, y, como resultado de las gestiones que ha venido promoviendo el gobierno ecuatoriano a través del Instituto de Promoción de Exportaciones e Inversiones (ProEcuador), adscrito al Ministerio de Comercio Exterior, se han generado grandes expectativas de que la demanda de China siga creciendo de manera sostenible. Adicionalmente, el gobierno ha firmado convenios de inversión con Qatar en diferentes sectores. Entre ellos, el comercio de productos agrícolas de calidad y exclusividad como las flores. La floricultura, por lo tanto, es uno de los sectores que más han incrementado sus exportaciones en los últimos años ${ }^{35}$. Según el Ministerio Coordinador de Producción, Empleo y Competitividad, Hasad Food, empresa del Estado de Qatar, creada en el año 2008, para invertir en el sector de la alimentación y agro-negocio a nivel mundial ${ }^{36}$, ha mostrado gran interés, en importar rosas ecuatorianas sin tener que pasar por el puerto de Amsterdam (MCPEC, 2014).

La apuesta por incrementar la producción de nuevas variedades de flores nuevamente evidencia unas políticas que buscan favorecer principalmente a las grandes empresas comerciales. Así, Expoflores, conformada por productores y comercializadores desde 1984 lidera al sector florícola. Adicionalmente, es una organización empresarial que incluso ha formado parte de la misión comercial para la apertura de nuevos mercados e inversiones en China (Carrasco Molina, 2015: 8). No solo esto, sino que es uno de los pocos gremios productivos y empresas que ya han establecido alianzas con la Universidad del Conocimiento Yachay, una empresa pública, para desarrollar nuevas tecnologías para el sector $^{37}$ (Revista Líderes, s/f). Por otro lado, la compañía privada Agroplantas, representante de la empresa alemana Rosen Tantau y parte de Expoflores, es también una 
de las principales beneficiarias de la política de cambio de la matriz productiva ${ }^{38}$. Esta empresa selecciona las variedades de rosa que se han adaptado al medio ecuatoriano y que podrán ser vendidas a los floricultores a nivel nacional para su posterior siembra y producción (El Telégrafo, Junio 11 de 2014).

Hasta ahora, se ha dicho que la producción de flores no ha implicado una concentración de tierra importante, sino un intensivo uso de capital y una concentración de agua por parte de las empresas florícolas (Martínez Valle, 2014: 142) ${ }^{39}$. No obstante, la revisión de los datos oficiales permite observar, a partir del año 2013, una tendencia al incremento de la desigualdad de las propiedades y a una progresiva concentración de la tierra. De las 571 haciendas productoras de flores, el 62\% tenía un promedio de 6,12 hectáreas, mientras que una minoría, el 10\%, tenía 37 hectáreas (ProEcuador, 2013: 3-4). Además, mientras que las hectáreas dedicadas al agronegocio de las rosas no sobrepasaban las 4,07 mil hectáreas en el año 2012, estas llegaron a las 5,47 mil hectáreas en el año 2013. Los datos proporcionados para el año 2013 dan cuenta de un total de 9.3 mil hectáreas para el cultivo total de flores, de los cuales las rosas ocupaban el 58,68\%, mientras que la gypsophila y clavel casi el $20 \%$ del total de la superficie plantada. Para el caso de la gypsophila la superficie plantada aumentó en un 130\%, mientras que en el caso del clavel, 626\%. (INEC, 2013: 47). Estos datos oficiales confirmarían que esta nueva dinámica de ampliación de la producción florícola con nuevos productos estaría generando acaparamiento de tierras, una situación que aparentemente no se habría dado hasta ahora.

Pese a que la generación de puestos de trabajo ha sido una de los argumentos a favor de la consolidación del monocultivo de flores, es bien conocido que el sector privado se ha nutrido de una abundante; y, por lo tanto, sumamente barata mano de obra proveniente de las comunidades indígenas y campesinas aledañas a las plantaciones. No obstante, estos sectores, si bien "han experimentado en los últimos diez años una progresiva transformación en sus patrones tradicionales de reproducción, en su nivel de organización social y, en general, en sus valores y modos de vida" han podido conservar sus minifundios y no han sido desposeídas de sus medios de producción (Martínez Valle, 2014: 142-143). Constituye, sin embargo, una mano de obra subordinada a las empresas florícolas que ha 
Tierras, territorios y procesos territoriales: Planteamientos teóricos y análisis de los procesos de acaparamiento de tierras

venido crecientemente confrontando problemas de salud debido a la alta exposición a pesticidas tóxicos y al incumplimiento de las normas de seguridad laboral; como también a la vulneración de sus derechos laborales y a conflictos entre sus valores y los de la lógica empresarial. Problemas que, en su gran mayoría afecta principalmente a las mujeres y jóvenes de la población indígena (Korovkin y Sanmiguel, 2007: 25-26). Al año 2005, Korovkin y Sanmiguel (2007) calculaban que solo 4 de las más de 400 empresas florícolas del Ecuador tenían sindicatos. Según un estudio de la Organización Internacional del Trabajo, OIT, existe una "resistencia absoluta" entre las empresas florícolas para aceptar sindicatos, por lo que "bloquean cualquier intento de sindicalización mediante el despido de los trabajadores involucrados" (Korovkin y Sanmiguel, 2007: 24).

\section{La región amazónica}

En la Amazonía, en los tres primeros siglos postconquista, tras un corto intento de explotación minera, el ordenamiento de la región quedó a cargo de las misiones religiosas, por lo que solo al final del siglo XIX algunos territorios comenzaron a ser objeto de procesos de colonización y de inversión de capital. En 1942, tras el conflicto fronterizo con Perú, el país identificó como urgente la defensa de su territorio amazónico. Pero, fue como resultado del descubrimiento de petróleo que, en la década de 1970, comenzó el auge del acaparamiento territorial en dicha región. Adicionalmente, en la última década, la construcción de dos importantes ejes viales entre la Amazonía y la Sierra dieron origen a una zona sub-montana especialmente intervenida por la ganadería, y las plantaciones de palma y de otros monocultivos.

\section{La expansión de la frontera petrolera y su relación con la infraestructura vial}

En 1969 la construcción del campo de la Shell, cercano a la ciudad del Puyo, dio inicio a la exploración de hidrocarburos en la Amazonía. Con las vías de acceso abiertas para la exploración petrolera en la década de 1970 se facilitó la migración de miles de colonos, atraídos por la relativa bonanza generada por el auge de la producción petrolera ${ }^{40}$. En 1972 un oleoducto comunicó los campos amazónicos con el puerto de Esmeraldas, 
dando inicio tanto a la exploración y a la extracción en gran escala. Lo cual no solo generó mayor deforestación, sino también grandes derrames de petróleo crudo en los bosques, destrucción de los cursos de agua, y contaminación atmosférica debido a la quema de gas. En 1986 se modificaron las áreas protegidas a fin de facilitar la exploración petrolera con base en una agenda basada en un nuevo discurso de "tecnologías de punta", "responsabilidad corporativa", y "contratación de servicios" por parte del Estado. En general, la tendencia predominante de la industria petrolera ha sido hacia la expansión, particularmente en el periodo que oscila entre 1982 y 1995, época en que se entregaron 9 bloques petroleros a las empresas. Actualmente, el nororiente de la Amazonía es uno de los lugares con mayor contaminación del país como resultado de las huellas dejadas por las empresas petroleras tanto en sus territorios como en la salud de la población.

Uno de los rasgos resaltantes de estos procesos es que la ampliación de la frontera petrolera ha estado acompañada por la construcción de infraestructura vial a fin de facilitar la comercialización de todo tipo de insumos y productos, y el transporte del petróleo. De allí que el gobierno haya apostado fuertemente por el proyecto Manta-Manaos. Este es un proyecto multimodal o un sistema interconectado de transporte (terrestre, ferroviario, aéreo y fluvial) que integra el puerto de Manta con la ciudad brasileña de Manaos ${ }^{41}$. Está considerado como un proyecto estratégico para Ecuador, ya que "permitiría que los productos nacionales no solo lleguen a Brasil, sino también a Asia sin necesidad de pasar por el canal de Panamá, lo cual reduciría costos y tiempo, y representaría un beneficio para los productos y productores ecuatorianos" (El Ciudadano, abril 4 de 2014) ${ }^{42}$. MantaManaos también forma parte del eje Amazónico de la Integración de la Infraestructura Regional Sudamericana (IIRSA) ${ }^{43}$ promovida por la UNASUR ${ }^{44}$. Los llamados ejes de integración y desarrollo, promovidos por el Consejo Suramericano de Infraestructura y Planeamiento (COSIPLAN) de la UNASUR, son franjas multinacionales de territorio en donde se concentran espacios naturales, asentamientos humanos, zonas productivas y flujos comerciales $^{45}$. Luego de que esta iniciativa se mantuviera congelada por un tiempo ${ }^{46}$, el avance en los últimos años se ha consolidado más del lado ecuatoriano que del brasileño, país que cuenta con otras posibles vías de acceso a los mercados asíaticos. En particular, el 
gobierno ecuatoriano ha estado inviertiendo agresivamente en la infraestructura vial y maritima (Puerto Providencia en la provincia del Napo y el Puerto de Aguas Profundas de la ciudad de Manta), que forman parte del eje Manta Manaos ${ }^{47}$.

La construcción de la refinería del Pacífico forma parte de este plan de inversiones públicas. La refinería, ubicada en el sitio El Aromo, con una extensión de 1 665,42 hectáreas, fue declarada como primera Zona Especial de Desarrollo Económico (ZEDE) para la refinación y petroquímica ${ }^{48}$. La refinería pretende alcanzar la soberanía energética a través del procesamiento de 300 mil barriles de petróleo por día, y establecer un parque industrial alrededor de la misma para la producción de derivados del petróleo para los encadenamientos productivos. El paquete accionario de la refinería está compuesto por el $51 \%$ de Petroecuador y el $49 \%$ de la empresa estatal petrolera de Venezuela, PDVSA. Hasta el momento, la Refinería ha avanzado en un 12\% de las obras contempladas, financiadas mayormente por Petroecuador ${ }^{49}$. El gobierno ecuatoriano espera la participación financiera de capitales chinos en el 30\% de las acciones (El Comercio, marzo 1 de 2015). Para esto, el gobierno ha firmado un acuerdo con la empresa estatal petrolera de China (CNPC) y el Banco Industrial y Comercial de este país, no solo para el financiamiento de la Refinería, sino también para la exploración y explotación de petróleo en la Amazonía (El Diario, Marzo 2 de 2015).

Una de las principlaes consecuencias del objetivo del Estado en explotar los recursos fósiles de la Amazonía ha sido la expansión de la frontera de recursos a los territorios donde mayormente habitan las comunidades y nacionalidades indígenas. De hecho, la vía fluvial del eje Manta-Manaos, que tiene como punto de partida a Puerto Providencia, ubicado a $80 \mathrm{~km}$ de Shushufindi y $40 \mathrm{~km}$ de Francisco de Orellana, pasa por los campos petroleros Panacocha y Tiputini, y llega a Nuevo Rocafuerte, previsto como un centro de atención de frontera y aeropuerto de turismo y transferencia de carga. La expansión del extractivismo, vinculada a la ampliación de la frontera extractiva afecta directamente al Parque Nacional Yasuní, que se encuentra en pleno eje Amazónico MantaManaos del IIRSA ${ }^{50}$. Desde hace más de dos décadas, las operaciones petroleras han afectado al Parque Nacional Yasuní ${ }^{51}$. Particularmente, en el bloque 43-ITT, llamado así 
Tierras, territorios y procesos territoriales: Planteamientos teóricos y análisis de los procesos de acaparamiento de tierras y territorios en Ecuador con posterioridad al 2008

por estar conformado por los campos petroleros Ishpingo, Tambococha y Tiputini y situado en pleno corazón del Parque se han encontrado reservas de crudo pesado, mezclado con gran cantidad de agua, por lo que es considerado de baja calidad,. De ser extraído ese petróleo, y debido a la cantidad de desechos que serían arrojados al entorno, las consecuencias sociales y los impactos ambientales para ese territorio amazónico son súmamente preocupantes ${ }^{52}$.

De hecho, el territorio del bloque ITT está habitado por los pueblos TagaeriTaromenani, pertenecientes a la nacionalidad Huaoran ${ }^{53}$, conocidos desde la década de los años 50 del siglo pasado como Pueblos Indígenas en Aislamiento Voluntario (PIAV), debido a su rechazo al contacto y a la colonización de sus territorios por las empresas petroleras. Estos indígenas ocupan la selva con una forma de poblamiento muy dispersa, y con ciclos de producción de alimentos que los llevan a cultivar chacras temporales, y a trasladarse a las áreas de pesca, caza o recolección para abastecerse de otros alimentos. La pesca ejerce un rol complementario, ya que estos grupos han habitado tradicionalmente los espacios de interior de la selva más que las riberas. Como resultado de los procesos de acaparamiento de sus territorios, el auto gobierno de esta población está siendo cuestionado por los intereses tanto de las empresas petroleras como del Estado, lo que pudiera conlleva el peligro del exterminio definitivo de estas poblaciones.

\section{A manera de conclusión}

Los conflictos por el control de los recursos naturales constituyen una constante histórica en América Latina. En la literatura académica el tema del 'acaparamiento de tierras' (land grabbing en inglés), y sus vínculos con las alzas de precio de las "commodities" agrícolas ha estado siempre vinculada a la cuestión agraria. El acaparamiento de territorios debido a la expansión de las fronteras de las actividades de empresas mineras, de hidrocarburos y forestales, agronegocio, etc., en ocasiones con el apoyo explícito de los Estados nacionales, constituye un fenómeno global mucho más reciente, con diferentes manifestaciones en cada contexto nacional y territorial. Los casos analizados en las tres macro-regiones del Ecuador nos permiten identificar tanto las

CAMPO-TERRITÓRIO: revista de geografia agrária. Edição especial, p. 76-115, jun., 2016 
Tierras, territorios y procesos territoriales: Planteamientos teóricos y análisis de los procesos de acaparamiento de tierras y territorios en Ecuador con posterioridad al 2008

transformaciones territoriales en marcha que están llevando al acaparamiento de los territorios, como las importantes diferencias que existen entre estos procesos contemporáneos con la cuestión agraria de los siglos anteriores, particularmente, en relación con los diferentes actores sociales.

En la práctica, el gobierno del Ecuador está apostando a la continuación de un modelo de "neo-extractivismo" basado en la consolidación de actividades productivas tradicionales, es decir, aquellos sectores que motorizaron la economía del país con la expansión de las exportaciones y de la concentración de los recursos productivos en siglos anteriores. En la construcción de un nuevo régimen de acumulación, hoy estas actividades han sido redefinidas por medio de su diversificación e incorporacón de valor agregado (p. ej., especies acuáticas y camarones producidos de la maricultura, nuevas especies de la floricultura, etc.), para vincularlas al mercado regional y mundial de manera estratégica y eficiente (soberanía energética, a través del procesamiento de petróleo o producción de agrocombustibles producidos de la caña de azúcar). En este nuevo contexto mundial, el rol del Estado ha cambiado: hoy más allá de facilitar estas actividades, el Estado se asocia con el sector privado y es inversor clave en el proceso de acumulación capitalista. Por lo tanto, surgen nuevas alianzas, que principalmente consolidan la participación del sector privado nacionalregional/internacional (empresas proveniente del Perú o Brasil) con el Estado nacionalregional/internacional (empresas estatales Chinas o de Qatar); y se asientan acuerdos transregionales con Estados de la región (IIRSA y su componente Manta-Manaos).

En la redefinición de las actividades productivas también es necesario establecer alianzas con nuevas organizaciones sociales que sean funcionales a los modelos de desarrollo propuestos en el cambio de esta matriz productiva. Esta inserción de organizaciones sociales a la dinámica productiva; no obstante, allí donde existen propuestas de modelos alternativos de gobernanza territorial que implican, entre otros, modelos de producción y desarrollo distintos, evidencian disputas y divisiones sobre el modelo de gestión territorial y el papel de las organizaciones sociales. Otro aspecto no menos importante, las transformaciones territoriales que están propiciando acaparamiento, a diferencia de otros momentos históricos, se dan en un entorno caracterizado por el agotamiento del ambiente biofísico y recursos

CAMPO-TERRITÓRIO: revista de geografia agrária. Edição especial, p. 76-115, jun., 2016 
naturales, que para muchas poblaciones que viven de ellos, significa su exterminio (la Amazonía o en el ecosistemas de manglar). Problema que no ha sido asumido por el Estado a nivel nacional, mucho menos a nivel subnacional.

Como una contribución adicional, este artículo quiere aportar en la concepción de nuevas políticas públicas relacionadas con el territorio con base en dos elementos que se dejan observar de las conclusiones aquí desarrolladas. El primer aspecto sugiere que los avances esbozados en la Constitución de 2008 no han resuelto ni la cuestión agraria ni territorial, lo que ha agravado los conflictos en territorio y ha concluído en la persistencia de una economía extractivista, en detrimento de los derechos colectivos de las poblaciones, y de la soberanía alimentaria de sus poblaciones y del país en general. De ahí que el principal obstáculo para la implementación de los principios constitucionales ha sido la incapacidad del Estado para superar la institucionalidad jurídica heredada de períodos anteriores.

Específicamente en lo que atañe a los derechos colectivos, en 2008, la Constitución explícitamente reconoció en el artículo 56 diferentes Nacionalidades como parte del Estado, y el artículo 363 las normas jurídicas de la justicia indígena con base en las tradiciones ancestrales de las comunidades, pueblos y Nacionalidades, con la salvedad de que estas no estuvieran en contradicción con el resto de normas constitucionales. Planteamientos que para los pueblos originarios significaban un importante logro, ya que implícitamente planteaban la reestructuración de la anterior división político-territorial del Estado, con base en sus reivindicaciones de autonomía y autogobierno sobre los territorios que ellos reclamaban como ancestrales.

Esto se ha manifestado en particular en los territorios amazónicos debido a las anteriores divisiones político-territoriales del Estado que entran en contradicción con los derechos territoriales supuestamente garantizados por la Constitución a las comunidades, pueblos y Nacionalidades indígenas. En la práctica el resultado ha sido un pluralismo legal que conspira contra los derechos de autonomía territorial de las comunidades, pueblos y Nacionalidades en general. Por ejemplo, no se ha creado ninguna Circunscripción Territorial Indígena (CTI), como plantea la Constitución, lo que revela la existencia de múltiples dificultades jurídicas, técnicas, socio-culturales, pero principalmente políticas,

CAMPO-TERRITÓRIO: revista de geografia agrária. Edição especial, p. 76-115, jun., 2016 
Tierras, territorios y procesos territoriales: Planteamientos teóricos y análisis de los procesos de acaparamiento de tierras y territorios en Ecuador con posterioridad al 2008

para la aprobación de la legislación secundaria requerida para un efectivo cumplimiento de las normativas constitucionales.

La principal dificultad, de índole jurídica es, por lo tanto, la posibilidad de fragmentación de la totalidad o una parte de las tierras colectivas y de facilitar libremente las transacciones de compra-venta de la tierra establecida en la normativa institucional vigente, la Ley de Desarrollo Agrario de 1994. Por un lado, esto generó que el único mecanismo de acceso a la tierra para pequeños agricultores, trabajadores agrícolas sea a través del mercado de tierra a precio comercial. Por otro lado, esto ocasionó la eliminación progresiva de la posesión colectiva de territorios de comunidades con derechos colectivos con el fin propiciar la transferencia del suelo al mercado para dar paso a la privatización de los recursos del subsuelo. La tierra es entendida solo como el suelo y sus recursos puede ser adjudicada en forma individual o colectiva, incluso en áreas protegidas y el Estado se reserva derechos sobre el subsuelo, los recursos naturales no renovables, y el espectro radioeléctrico (cfr. art. 408).

Desde un punto de vista más general, de diseño institucional, esta dificultad se traduce en la escasa coordinación entre los planteamientos normativos diseñados por las agencias de planificación central (p.ej. SENPLADES, Ministerio Coordinador de Producción, Empleo y Competitividad, etc.) y las políticas diseñadas por los ministerios y agencias públicas sectoriales a diferentes escalas territoriales; así como entre las agencias del Estado central ('desde afuera' o 'desde arriba') con los gobiernos sub-nacionales y las entidades creadas para la implementación de las políticas a escalas territoriales (p.ej. el Instituto para el Ecodesarrollo Regional Amazónico). De la Constitución a la implementación, por lo tanto, no están suficientemente claros los mecanismos; p. ej. la la Estrategia Nacional para la Igualdad y la Erradicación de la Pobreza de la SENPLADES no identifica los mecanismos necesarios para implementar los componentes sociales y ambientales al proceso de transformación de la matriz productiva.

La agenda de modernización del Estado en los territorios debería suponer la ampliación y mejoramiento de la oferta de bienes públicos y el incremento de la eficacia de las agencias públicas. En la práctica lo que ha ocurrido, es el incremento del número de

CAMPO-TERRITÓRIO: revista de geografia agrária. Edição especial, p. 76-115, jun., 2016 
Tierras, territorios y procesos territoriales: Planteamientos teóricos y análisis de los procesos de acaparamiento de tierras y territorios en Ecuador con posterioridad al 2008

ministerios y funcionarios públicos, lo que ha generado en una excesiva burocratización y el incremento del papeleo en los trámites de los ciudadanos ante las autoridades públicas; además de la creciente verticalidad (y escasa transparencia) de los mecanismos de evaluación y monitoreo que poco informan sobre la coherencia de los resultados y rendimientos del trabajo que se está desarrollando en los territorios en relación con los objetivos estratégicos constitucionales (p.ej. soberanía alimentaria). Todo esto no ha incidido con la eficiencia esperada en el fortalecimiento de los vínculos entre el Estado central y la solución de los problemas en los territorios rurales. Lo que, por supuesto, implica, por un lado, la necesidad de cambios en las estructuras jurídico-políticas del Estado. Por otro lado, plantea la necesidad de que los proyectos del Estado que buscan tener impacto a diferentes escalas territoriales puedan ser apropiados por las organizaciones de esos diferentes niveles territoriales a fin de que les den continuidad.

Esto último nos lleva al segundo aspecto. Los preceptos constitucionales que consagran la participación de las comunidades y las organizaciones territoriales en el diseño y la implementación de las políticas públicas tenía como objetivo general contribuir a la democracia participativa. Lo que ha dado origen a diferentes tipos de procesos. Por una parte, la movilización, lucha, y resistencia en contra de la ocupación de los territorios campesinos, indígenas, etc. Por otra parte, procesos como las demandas para ser tomadas en cuenta por las empresas en condiciones contractuales como trabajadores asalariados (caso de las empresas florícolas) o como socios (como es el caso de los agricultores bajo contrato en los planes y proyectos del Estado y/o de las empresas privadas de la caña de azúcar). Heterogeneidad de procesos que, de acuerdo a las lecciones extraídas de los casos de estudio, frecuentemente han estado vinculados a los impactos socio-económicos, culturales y ambientales de los proyectos de inversión de las empresas extractivas.

No obstante, el análisis de los casos también revela que en ocasiones las inversiones son vistas como positivas por razones económicas; mientras que, en otras, la revalorización de los patrones tradicionales de utilización de la biodiversidad constituye el principal medio para fortalecer su bienestar material, el fortalecimiento de sus derechos colectivos y la

CAMPO-TERRITÓRIO: revista de geografia agrária. Edição especial, p. 76-115, jun., 2016 
soberanía alimentaria. Estas dualidades reflejan los intereses antagónicos que pueden darse en estos procesos.

No obstante, a fin de garantizar los derechos de la Naturaleza y sus vínculos con los derechos colectivos, la Constitución también reconoció a todos los ciudadanos el derecho a vivir en un ambiente sano y libre de contaminación. Lo que generó ciertos intentos de incluir aspectos no solo sociales sino ambientales en la agenda de cambios en la matriz productiva y energética (p.ej. a través de la Estrategia Nacional para la Igualdad y la Erradicación de la Pobreza de la SENPLADES). Pero después de ocho años, los resultados no siempre han sido acordes con los otros objetivos planteados por la la Asamblea Constitucional de Montecristi. Por ejemplo, se construye una refinería y eso constituye un cambio en la matriz energética, pero la refinería puede generar efectos muy nocivos para los ecosistemas de los bosques circundantes (Bosque húmedo de pachoche en la cercanía de la comuna El Aromo donde se construye la refinería). Lo que genera procesos de transformación de dichos ecosistemas que no pueden ser diagnosticados a profundidad por los estudios de impacto ambiental ex ante. Por lo que esos supuestos estudios de impacto ambiental frecuentemente se convierten en una 'luz verde' para la implementación de los proyectos diseñados 'desde arriba'. En este sentido no habido cambio en la manera cómo se ha concebido la política pública en comparación con las décadas neoliberales.

Lo importante es cuestionar ¿qué efectos reales va a tener un proyecto sobre los problemas previamente diagnosticados?; y, ¿qué efectos negativos directos, o impactos indirectas tienen tanto sobre el territorio y sus ecosistemas, como más allá de él?; por último, y lo más importante, ¿cómo será evaluado el diseño del proyecto por las poblaciones locales? En otras palabras, ¿responde el proyecto a las estrategias y demandas de las poblaciones locales?; y, por último ¿cómo será evaluado el proyecto ex post, es decir después de su implementación en el territorio? Preguntas todas que no pueden ser respondidas por una planificación 'burocrática' (desde arriba) que no toma en cuenta las demandas de autonomía territorial de las poblaciones amazónicas.

El artículo demuestra, finalmente, la necesidad de fortalecer 'de abajo arriba' la gobernabilidad democrática mediante el empoderamiento de las organizaciones de la 
sociedad civil, desde las comunidades hasta los niveles jerárquicos más altos de gestión de los territorios subnacionales en su capacidad para diseñar e implementar sus propios proyectos. La participación en sí misma no es suficiente, si sus miembros no disponen de una comprensión íntegra de lo que se está negociando. Por lo que es vital la capacitación sobre las herramientas legales y los instrumentos burocráticos con los que pudieran contar para implementar sus propias agendas de vida. Un instrumento vital para el logro de estos objetivos es la construcción de mesas de diálogo para la solución de los conflictos (territoriales, culturales, económicos, etc.) a diferentes niveles. Para la sostenibilidad de los acuerdos a los que se pueda llegar en dichas mesas es indispensable que se generen las condiciones políticas que los sustenten.

\section{Notas}

${ }^{1}$ Registro Oficial No. 351 de Diciembre 29 de 2010.

2 Este Comité está conformado también por el Ministro Coordinador de Producción, Empleo y Competitividad, de Política Económica, de Sectores Estratégicos, de Conocimiento y Talento Humano, además del Secretario Nacional de Planificación y Desarrollo y de Educación Superior, Ciencia, Tecnología e Innovación.

${ }^{3}$ Decreto Ejecutivo 1505 de mayo 6 de 2013.

${ }^{4}$ Hoy existen diversas instituciones estatales y académicas, como el Viceministerio de Acuacultura y Pesca, la Subsecretaría de Recursos Pesqueros, Instituto Nacional de Pesca, la Corporación de Promoción de Exportaciones e Inversiones, Dirección Nacional de Espacios Acuáticos (DIRNEA), Centro Nacional de Acuicultura e Investigaciones Marina de la Escuela Superior Politécnica del Litoral (ESPOL), entre otros.

5 Estas incluían, entre otros, la devolución y reducción de impuestos por exportación, exoneración de aranceles para el ingreso de insumos, la promulgación de leyes dirigidas a la condonación de las deudas de los camaroneros, otorgación de créditos preferenciales y de bajo interés ante organismos multilaterales a través de las Corporación Financiera Nacional.

${ }^{6}$ El (re) crecimiento de la exportación de camarones se ha favorecido adicionalmente por la presencia del llamado "síndrome de muerte temprana" del marisco en Asia, que ha provocado precios internacionales más altos (Expreso, Junio 17 de 2014).

7 Se trata del cultivo de productos marinos en tanques ubicado en mar abierto (Viceministerio de Pesca y Acuacultura del Ecuador, 2015).

${ }^{8}$ Un estudio del Banco Central reconoció en el año 2003 que el impacto ambiental más dañino de esta actividad se daba con la ubicación y la extensión de las piscinas en el frágil ecosistema del manglar (Marriot, 2003: 39). Otros impactos son producidos por el bombeo del agua, la contaminación del agua y la introducción de especies nuevas a ecosistemas frágiles (Marriot, 2003: 40 y 41).

${ }^{9}$ La información disponible más actualizada corresponde al CLIRSEN, con base a información satelital publicada en el año 2007.

${ }_{10}$ Por su parte, el estudio de FAO hace mención que la mayor parte de la superficie de manglares fue convertida y utilizada para la acuicultura, la producción de sal y la agricultura (FAO, 2005: 1).

${ }^{11}$ El manglar está considerado como un bien nacional de uso público, patrimonio forestal del Estado, bosque protector, ecosistema altamente lesionable y patrimonio nacional de áreas naturales del Estado.

${ }^{12}$ El Acuerdo Interministerial 020 del Registro Oficial 366 del año 1990 permitió la concesión no sólo de zonas de playa y bahía, sino de bosques de manglar por un lapso de 10 años renovables, a través de la emisión

CAMPO-TERRITÓRIO: revista de geografia agrária. Edição especial, p. 76-115, jun., 2016 
de informes convenientes a los intereses emitidos por las autoridades de turno (Góngora y Benavides, 2007:112). También, la Ley Forestal y de Conservación de Vida Silvestre de 2004, pese a reconocer al manglar como un bien del Estado no susceptible de posesión o apropiación, permitió su concesión mediante reglamento.

${ }^{13}$ Entre 1999 y 2006, se dio una leve recuperación del ecosistema manglar, atribuible, de acuerdo a FAO, a una combinación de factores, como el abandono de las piscinas debido a la plaga "mancha blanca", el rompimiento de muros de las camaroneras por la fuerza del mar o acciones de grupos ecologistas, y el efecto que tuvo políticas de protección, recuperación y control de la tala ilegal del manglar (FAO, 2005: 6).

${ }^{14}$ En el año 1993 se constituyó la Cámara Nacional de Acuacultura (CNA), constituyéndose en la principal articulación entre el Estado y el sector privado, vinculada a la reproducción, cultivo, procesamiento y comercialización de especies acuáticas y actividades conexas (empresas empacadoras y fábricas de balanceado), en especial de camarones.

${ }^{15}$ A este se fueron complementando una serie de decretos como el Decreto Ejecutivo 1442 de noviembre de 2008 sobre reformas al pago por regularización, el Decreto Ejecutivo 261 de marzo de 2010 sobre la extensión de las camaroneras y la afiliación de empleados, el Decreto Ejecutivo 284 de marzo de 2010 que modifica el Decreto Ejecutivo 261 y el Decreto Ejecutivo 397 de junio de 2010 que amplía el plazo de regularización de la industria del camarón.

${ }^{16}$ El decreto condicionó esta regularización a la reforestación en el plazo de un año, de acuerdo a un porcentaje de la superficie cultivable.

${ }^{17}$ Este marco institucional, si bien otorga protección a los pescadores artesanales y recolectores comunitarios y sus prácticas sustentables, también concedió a la industria camaronera el plazo de un año para la regularización de tierras ilegalmente ocupadas y explotadas en área del manglar durante las últimas décadas (Art. 16, LORSA). En abril de 2009 C-CONDEM - en representación de los pueblos ancestrales del manglar interpuso una demanda de inconstitucionalidad del decreto 1391 ante la Corte Nacional de Justicia.

${ }^{18}$ El trabajo de incidencia política desarrollado por la C-CONDEM en los años de 1998 y 1999 jugó un papel determinante en la aprobación de dicho decreto.

${ }^{19}$ Se calcula que para ese año, 19 organizaciones manejaban bajo esta figura 20.000 hectáreas de manglar en El Oro, Guayas, Esmeraldas.

${ }^{20}$ El Acuerdo Ministerial 29 de abril Publicado en el Registro Oficial 936 del 18 de abril de 201 establece la tarea de los Gobiernos Autónomos Descentralizados (GADs) de declarar las áreas protegidas en sus circunscripciones territoriales y la facultad de la Autoridad Ambiental Nacional (AAN) de aprobar, coordinar, dar seguimiento, monitorear y evaluar las áreas protegidas de las GADs que fueren incorporadas en el Sistema Nacional de Áreas Protegidas (SNAP).

${ }^{21}$ De manera secundaria, la caña se utiliza para la generación de alimentos para ganado, fabricación de abonos. Además, de su bagazo actualmente se obtiene electricidad y papel.

${ }^{22}$ Otros ingenios con menos incidencia en el territorio son Isabel María, IANCEM y Monterrey (Cueva García 2001: 11).

${ }^{23}$ En el siglo XIX se instaló el primer ingenio azucarero llamado Rocafuerte cerca del cantón Naranjito. A finales de ese siglo ya se habían asentado los ingenios Progreso, Valdés, San Carlos, Aztra (La Troncal), y otros (Cueva García, 2001: 40).

${ }^{24}$ Anteriormente, ya se habían dado iniciativas privadas para la generación de bioetanol. Por ejemplo, la compañía La Fabril viene produciendo biodiesel del aceite de palma aceitera desde el año 2005 y exportando a la compañía estadounidense EarthFirst Technologies.

${ }^{25}$ Se trata de un agrocombustible compuesto inicialmente del 5\% de etanol proveniente de la caña de azúcar y 95\% de la gasolina base. Hasta Julio de 2013 se habían despachado 136 millones de litros de gasolina EcoPaís en 39 gasolineras de Guayaquil. Con este proyecto se espera ampliar la disponibilidad de biocombustibles a todas las gasolineras del país. También se espera incrementar proporcionalmente la composición del etanol en la gasolina hasta llegar al 15\% a partir del año 2019. Esta iniciativa ha generado un ahorro neto al Estado de 14 millones de dólares (El Telégrafo, Octubre 6 de 2013 y Ecuador Al Instante, Septiembre 2013).

CAMPO-TERRITÓRIO: revista de geografia agrária. Edição especial, p. 76-115, jun., 2016 
${ }^{26}$ Por ejemplo, Marcelino Mariedueñas, cantón de influencia del Ingenio San Carlos tienen un Gini de 0,91, el cantón Milagro, de influencia del Ingenio Valdez, de 0,75, y La Troncal de incidencia de Ecudos, de 0,84.

${ }^{27}$ Estas asociaciones forman parte de la Federación Nacional de Trabajadores Agroindustriales Campesinos e Indígenas Libres del Ecuador (FENACLE).

${ }^{28}$ El Plan Tierras fue implementado desde octubre de 2009 hasta diciembre de 2013, medida que buscaba intervenir aproximadamente 2,5 millones de hectáreas de tierra con el objetivo de reducir el coeficiente de Gini de desigualdad en la redistribución de la tierra de 0,80 a 0,70. El alcance de este plan ha sido cuestionado por diversas organizaciones sociales.

${ }^{29}$ En el año 2013, se calculaba el aporte anual de los ingenios es de 9`500 mil libtros mientras de los artesanos 500 mil libtros de 99,8 grados (El Telégrafo, diciembre 2013).

${ }^{30}$ El ATPDEA permitía el ingreso de flores y otros productos ecuatorianos al mercado norteamericano con arancel cero. Una vez eliminado en el año 2013, según el sector privado, se redujo la capacidad competitiva de las compañías de exportadoras que son gravadas con un 6,7 de arancel para ingresar sus productos a los Estados Unidos (FlorEcuador, 2014: 9).

${ }^{31}$ Entre 1990 y 1994 el salario mínimo de Ecuador era entre 20 y 25\% menor en comparación al de Colombia (BCE 2002 y Banco de la República de Colombia 2005) y los niveles de flexibilización laboral eran mayores en Ecuador. El cumplimiento de las leyes laborales era notablemente más débil y no representaba una preocupación para el sector empresarial. A esto se suma la debilidad del sindicalismo rural (Korovkin y Sanmiguel, 2007: 23).

${ }^{32} \mathrm{Se}$ incluyen rosas, flores de verano, flores tropicales, entre otras.

${ }^{33}$ El Ecuador produce más de 300 variedades de rosas rojas y de otros colores, además de 100 variedades de flores tropicales.

${ }^{34}$ En palabras del sector privado China “está en la misma coyuntura que estuvo Rusia en la década de los 90: una naciente clase rica, que tiene sed de consumo y quiere occidentalizarse en sus costumbres" (Carrasco, 2015).

${ }^{35}$ Otros sectores son el banano y plátano, productos de cuidado personal y del hogar, y alimentos procesados (El Telégrafo, Octubre 28 de 2014).

${ }^{36}$ En el año 2014 se calculaba que las compras de tierra hechas por esta empresa para ejecutar 14 grandes inversiones en fincas de trigo y ganado ovino en cuatro estados de Australia abarcaban 287.000 hectáreas. En: http://farmlandgrab.org/post/view/23624-qatari-government-buys-up-14-000-hectares-of-prime-southaustralian-farmland

37 Otros objetivos de esta alianza son mejorar la genética del ganado, fomentar el emprendimiento de la industria de software, innovar la industria bioquímica, etc.

${ }^{38}$ De acuerdo al Vicepresidente Jorge Glas Espinel "Estamos viendo innovación ecuatoriana, aumento de las exportaciones, se está generando valor agregado y mano de obra; por esto, Agroplantas sí cumple con varios de los preceptos para ser considerada dentro del cambio de la Matriz Productiva, que no solamente son las grandes industrias, sino también son los agricultores" (Vicepresidencia de la República, Junio 10 de 2014).

${ }^{39} \mathrm{El}$ autor reconoce que ha existido concentración de agua por las empresas florícolas por la alta demanda de este recurso para la producción de flores Se calcula que se utilizan aproximadamente 900.000 litros de agua por mes y por hectárea (Martínez Valle, 2014: 142).

40 Este proceso ya se había iniciado durante el período en que se implementó la Ley de Fomento Agropecuario y Colonización (1964-1973).

${ }^{41}$ El recorrido del proyecto se inicia en el Puerto de Manta, en la provincia de Manabí, continua por Portoviejo y Quevedo en la provincia de Los Ríos. Desde aquí inicia el ascenso a la sierra ecuatoriana, pasando por La Mana de la provincia de Bolívar, y Zumbahua de la provincia de Cotopaxi y de allí hasta Latacunga, capital de la provincia. A partir de aquí, según Mancheno y Piedra (2008: 31), el proyecto no tiene una definición clara. Existen al parecer dos opciones: la primera, es seguir en dirección a Quito y luego al Tena; y la segunda opción, y la más controversial, es la que iría de Latacunga directamente hasta el Tena (prevista la construcción de un aeropuerto internacional de carga) pasando por el Parque Nacional Llanganates. Desde la ciudad de Tena hasta el Coca, pasando por el Parque Nacional Sumaco Napo-Galeras, ambas ciudades amazónicas, donde hay la opción de mejorar la vía actual o construir una carretera de $138 \mathrm{~km}$

CAMPO-TERRITÓRIO: revista de geografia agrária. Edição especial, p. 76-115, jun., 2016 
a orillas del rio Napo. La vía fluvial tiene su punto de partida en Puerto Providencia, ubicado a $80 \mathrm{~km}$ de Shushufindi y $40 \mathrm{~km}$ de Francisco de Orellana, y muy cerca del Parque Nacional Yasuni.

${ }^{42}$ De acuerdo a Varilla (sf, tomado de Mancheno y Piedra, 2008: 45), la vía que pasa por el Canal de Panamá es de 45 días, cuando la Manta Manaos seria de 15 días.

${ }^{43}$ Foro Técnico para temas relacionados con la planificación de la Integración física regional de los países parte de la Unión de Naciones Suramericanas (UNASUR).

${ }^{44} \mathrm{La}$ Unasur fue creada por los presientes suramericanos en el año 2008 como espacio de articulación y diálogo político de alto nivel que involucre a los gobiernos de los doce países de América del Sur y tiene como una de sus prioridades el desarrollo de infraestructura para la interconexión de la región. En: http://www.iirsa.org/Page/Detail?menuItemId=27

${ }^{45}$ En: http://www.iirsa.org/Page/Detail?menuItemId=57

${ }^{46}$ Se hablaba de un enfriamiento de las relaciones entre Ecuador y Brasil a raíz de la salida y confiscación de Odebrecht.

${ }^{47}$ El gobierno ha invertido aproximadamente 1.300 millones de dólares para la construcción del eje vial entre Manta y Puerto Providencia en el río Napo. En septiembre de 2013 se estaba licitando el estudio de consultoría "para el mejoramiento de las condiciones de navegación del trecho de 130 kilómetros entre Puerto Providencia y la frontera con el Perú, proyecto calificado como prioritario por UNASUR, cuyas obras serán construidas con financiamiento brasileño" (Cancillería, Septiembre 19 de 2013).

${ }^{48}$ Las ZEDES, cuyo objetivo es fomentar las inversiones de capital, son figuras institucionales creadas por el Código Orgánico de la Producción, Comercio e Inversiones (COPCI), como parte de la estrategia de transformación a través de la sustitución selectiva de importaciones (El Telégrafo, diciembre 2 de 2015).

${ }^{49} \mathrm{La}$ empresa brasilera Odebrecht ha estado encargada de la adecuación de los terrenos y de la construcción del acueducto por donde se transportará el agua desde la represa La Esperanza a la Refinería (El Comercio, marzo 1 de 2015).

50 También son afectadas la Reserva de Producción Faunística del Cuyabeno y la Reserva Biologica Limoncocha.

${ }^{51}$ El bloque 16, dentro del parque, ya lleva tiempo siendo explotado por la empresa Repsol.

52 En: http://www.amazoniaporlavida.org/es/Parque-nacional-Yasuni/el-proyecto-itt-bloque-43-y-el-bloque31.html.

${ }^{53}$ La población indígena amazónica es de unos 225.000 habitantes, lo que equivale a aproximadamente el $35 \%$ de la población total de la región. Esta población está compueta por diez Nacionalidades (Kichwa, Shuar, Achuar, Huaorani, Siona, Secoya, Shiwiar, Andoa, Sapara y Cofán).

\section{Bibliografía}

Bonilla, O, Maldonado, P., Silveira, M. y Bayón, M. (2015). "Nudos cruciales críticos en Ecuador: dinámicas, cambios y límites en la reconfiguración territorial del Estado". (documento inédito).

Borras Jr., Saturnino M., Kay, C., Gómez, S. y Wilkinson, J. (2012). "Land grabbing and global capitalist accumulation: key features in Latin America". En Canadian Journal of Development Studies/Revue canadienne d'études du développement 33(4): 402-416.

Cámara Nacional de Acuacultura (2012). "El sector camaronero trabaja en la protección y recuperación del manglar". En Revista Aquacultura, edición 89, Enero-Febrero de 2012: 14-15. 
Cámara Nacional de Acuacultura (2012). ¿Ambientalismo sesgado, cinismo o justificación de su ineficiencia? En Aquacultura, edición 90, Marzo - Abril de 2012: 10-11.

Carrasco Molina, Jennie (2014). "China: un gran mercado en potencia". En Revista Flor Ecuador, No 81, Octubre 2014.

Cancillería (2013). "Avances en la ejecución del eje Manta-Manaos". Nota informativa Septiembre 19 de 2013. Visita Abril 20 de 2014 http://cancilleria.gob.ec/avances-en-laejecucion-del-eje-manta-manaos/

CLIRSEN, Ministerio del Ambiente y Programa de Manejo de Recursos Costeros (2007). Resumen Ejecutivo. Actualización del Estudio Multi Temporal de Manglares, Camaroneras, y Áreas Salinas en la Costa Continental Ecuatoriana al año 2006.

Cueva García, Javier Enrique (2001). Instalación de una planta productora de alcohol a partir de la caña de azúcar en la provincia del Guayas para el uso en vehículos. Proyecto de grado previo a la obtención del título de economista con mención en gestión empresarial, especialización finanzas. Instituto de Ciencias Humanísticas y Económicas. Guayaquil: Escuela Superior Politécnica del Litoral (ESPOL).

Ericsson, Karin (2013). Tierra + campesino= ¿Soberanía Alimentaria? El uso de la tierra de la hacienda La Indiana después de la transferencia de tierras a asociaciones campesinas. Trabajo final para el curso Soberanía Alimentaria y Políticas Públicas FLACSO Ecuador (documento inédito).

FlorEcuador (2015). "Cambio de matriz productiva". Revista Flor Ecuador No. 47. Febrero 2015. Visita mayo 1 de 2015 http://issuu.com/revistaeyf/docs/revista_47

FlorEcuador (2014). "A conquistar mercados masivos". Revista Flor Ecuador No. 76, Abril 2014. Visita mayo 1 de 2015 http://issuu.com/revistaeyf/docs/revista_47

Instituto de Promoción de Exportaciones e Inversiones, ProEcuador (2013). Análisis Sectorial de Flores 2013 de la Dirección de Inteligencia Comercial e Inversiones.

Instituto Nacional de Estadísticas y Censo, INEC (2013). Encuesta de Superficie y Producción Agropecuaria Continua 2013.

Instituto Nacional de Estadísticas y Censo, INEC (2012). Encuesta de Superficie y Producción Agropecuaria Continua 2012.

FAO (2005). Evaluación de los recursos forestales mundiales 2005. Estudio temático sobre manglares, Ecuador.

CAMPO-TERRITÓRIO: revista de geografia agrária. Edição especial, p. 76-115, jun., 2016 
Góngora L. y Benavides M. (2007). Certificando la destrucción. Análisis integral de la certificación orgánica a la acuacultura industrial de camarón en Ecuador. Quito: CCONDEM.

Gudynas, Eduardo (2009). "Diez tesis urgentes sobre el nuevo extractivismo. Contextos y demandas bajo el progresismo sudamericano actual". En Extractivismo, política y sociedad, Acosta, Alberto, et. al (Coord.):187-225. Quito: CAAP y CLAES.

Haesbaert, Rogério (2008). "Dos múltiplos territórios à multiterritorialidade". En A emergência da multiterritorialidade: a ressignificação da relação do humano com o espaço, Heidrich, Álvaro et. al (Coord.). Canoas/Porto Alegre: ULBRA/EdUFGRS.

Korovkin Tania y Sanmiguel Valderrama Olga (2007). "Estándares de trabajo e iniciativas no estatales en las industrias florícolas de Colombia y Ecuador". En Revista Iconos, No. 29: 15-30.

Larrea Maldonado, Carlos (2008). "Tenencia de la tierra, cambios agrarios y etnicidad indígena en el Ecuador: 1954-2000”. En Desarrollo rural y neoliberalismo, Liisa L. North y John D. Cameron (eds.): 129-146. Quito: Universidad Andina Simón Bolívar, Sede Ecuador y Corporación Editora Nacional.

Líderes (s/f). "Yachay genera altas expectativas". Revista Líderes. Visita mayo 1 de 2015 http://campanias.elcomercio.com/Especial-Innovacion/yachay.html\#.VaAuBV6prwI

Llambí, Luis (2010) “¿Hacia una nueva sociología rural latinoamericana?: La sociología rural del siglo XXI y el reto de la interdisciplinariedad". Presentación power point. Congreso de la Asociación Latinoamericana de Sociología Rural (ALASRU) de Porto Galhinas, Pernambuco, Brasil.

Mancheno, Diego y Andrés Piedra (2008). La Manta-Manaos, estudio económico regional: alcances, riesgos y potencialidades. Quito: Grupo FARO.

Marriott García Francisco (2003). Apunte de Economía Nº. 29, Dirección General de Estudios, Banco Central, "Análisis del Sector camaronero" 2003. En http://contenido.bce.fin.ec/documentos/PublicacionesNotas/Catalogo/Apuntes/ae29.pdf

Martínez Valle, Luciano (2012). "El caso de Ecuador". En Dinámicas del mercado de la tierra en América Latina y el Caribe: concentración y extranjerización de tierras, Soto de Fernando y Sergio Gómez (Eds.): 231-252. Roma: FAO.

Martínez Valle, Luciano (2014). "De la hacienda al agronegocio: agricultura y capitalismo en Ecuador". En Capitalismo: tierra y poder en América Latina (1982-2012), Volumen II, Almeyra, Guillermo, Luciano Concheiro Bórquez, Joao Marcio Mendes Pereira, Carlos

CAMPO-TERRITÓRIO: revista de geografia agrária. Edição especial, p. 76-115, jun., 2016 
Walter Porto-Goncalves (Coord.): 123 - 155. México: Ediciones Continente, CLACSO y Universidad Autónoma Metropolitana.

Maíz Soya (2014). "Tres destinos concentran el 95\% de las exportaciones camaroneras". Revista Técnica edición Diciembre 2013 - Enero 2014. Visita mayo 1 de 2015 http://maizysoya.com/tres-destinos-concentran-el-95-de-las-exportaciones-camaroneras/

Ministerio Coordinador de Producción, Empleo y Competitividad (2013). "Grupo Gloria invierte en Ecuador para producción de biocombustibles". Nota informativa noviembre 25 de 2013. Visita mayo 1 de 205 http://www.produccion.gob.ec/grupo-gloria-invierte-enecuador-para-produccion-de-biocombustibles/

Ministerio de Agricultura, Ganadería y Pesca, MAGAP (2014). "MAGAP impulsa producción de caña de azúcar para biocombustibles". Nota informativa de enero 2 de 2014. Visita mayo 1 de 2015 http://www.agricultura.gob.ec/magap-impulsa-produccion-de-canade-azucar-para-biocombustible/

Ministerio de Agricultura, Ganadería y Pesca, MAGAP (2013). En Hacienda La Indiana se realizó primera siembra de caña de azúcar para biocombustible. Nota informativa de octubre 4 de 2013. Visita mayo 1 de 2015 http://www.agricultura.gob.ec/en-hacienda-laindiana-se-realizo-primera-siembra-de-cana-de-azucar-para-biocombustible/

Ministerio de Comercio Exterior (2014). "Se exponen beneficios del acuerdo de cooperación entre Ecuador y Qatar". Nota informativa marzo 26 de 2014. Visita mayo 1 de $2015 \mathrm{http} / / \mathrm{www} . c o m e r c i o e x t e r i o r . g o b . e c / s e-e x p o n e-b e n e f i c i o s-d e l-a c u e r d o-d e-$ cooperacion-entre-ecuador-y-qatar/

Ministerio Coordinador de Producción, Empleo y Competitividad (2014). "Qatar encuentra oportunidades de inversión en Ecuador". Nota informativa octubre 24 de 2014. Visita mayo 1 de 2014 http://www.produccion.gob.ec/qatar-encuentra-oportunidades-de-inversion-enecuador/

Observatorio Ciudadano de Impactos Socio Ambientales del Proyecto Eje Multimodal Manta Manaos en Ecuador (2010). Recomendaciones para efectivizar la gobernanza transparente y democrática en el proceso de implementación de corredores de integración en el Ecuador. Quito.

Rocha Menocal, Alina (2015). Citizens and Engagement beyond Slogans. En Prodavinci (www.prodavinci.com) julio 1 de 2015.

SENPLADES. (2012). Folleto informativo. Transformación de la Matriz Productiva. Quito, Pichincha, Ecuador: SENPLADES.

CAMPO-TERRITÓRIO: revista de geografia agrária. Edição especial, p. 76-115, jun., 2016 
Secretaría del Agua (2014). "En proyecto DAUVIN inició colocación de rejillas para obra de toma". Julio 8 de 2014. Visita mayo 1 de 2015 http://www.agua.gob.ec/en-proyectodauvin-inicio-colocacion-de-rejillas-para-obra-de-toma/

SIPAE (2010). "Concentración de la tierra y control de la comercialización: desafíos de cambio para una efectiva reforma agraria en el Ecuador". En Alerta Agraria No. 18: 1-14.

Viceministerio de Acuacultura y Pesca. Maricultura, la nueva cadena productiva para el Ecuador. Boletín $\mathrm{N}^{\circ}$. 018/VAP. Abril 13 de 2015. Visita mayo 1 de 2015 http://www.viceministerioap.gob.ec/subpesca2421-mariculturala-nueva-cadena-productivapara-el-ecuador.html

Vicepresidencia de la República. "Vicepresidente Jorge Glas Espinel recorrió Agroplantas". Nota informativa, junio 10 de 2014. Visita mayo 1 de 2015 http://www.vicepresidencia.gob.ec/vicepresidente-jorge-glas-recorrio-agroplantas/

\section{Artículos de periódicos}

Andes (2013). "Ecuador producirá 800 millones de litros de etanol para programa de biocombustible". Octubre 7 de 2013. Visita mayo 1 de 2015 http://www.andes.info.ec/es/economia-reportajes/ecuador-producira-800-millones-litrosetanol-programa-biocombustible.html

Diario Expreso (2014). “Auge del camarón por crisis tailandesa”. Junio 17 de 2014. Visita $\begin{array}{llll}\text { mayo } & 1 & \text { de }\end{array}$ http://expreso.ec/expreso/plantillas/nota_print.aspx?idArt=6437506\&tipo=2

Diario Expreso (2014). "Ecuador se aventura a cultivar camarón y alga". Mayo 10 de 2014. Visita mayo 11015 http://expreso.ec/expreso/plantillas/nota.aspx?idart=6198833\&idcat=19308\&tipo=2

Diario Expreso (2014). "Ya hemos sembrado camarones en el mar". Marzo 3 de 2014. Visita mayo 11015 http://expreso.ec/expreso/plantillas/nota_print.aspx?idArt=5804871\&tipo=2

Ecuador al Instante (2013). "80 mil hectáreas de caña para producir biocombustibles". Septiembre 25 de 2013. Visita mayo 1 de 2015 http://ecuadoralinstante.com/80-milhectareas-de-cana-para-producir-biocombustibles/

El Ciudadano (2014). "Brasil y Ecuador analizan avances del Manta Manaos". Abril 4 de 2014. Visita abril 15 de 2014 http://www.elciudadano.gob.ec/brasil-y-ecuador-analizanavances-del-manta-manaos/

CAMPO-TERRITÓRIO: revista de geografia agrária. Edição especial, p. 76-115, jun., 2016 
El Comercio (2015). "La suerte de la Refinería del Pacífico todavía depende del dragón chino". Sección Actualidad marzo 1 de 2015. Visita mayo 1 de 2015 http://www.elcomercio.com/actualidad/refineriadelpacifico-financiamiento-china-ecuadorpetroleo.html.

El Diario. "La Refinería del Pacífico tiene un 12\% de avance". Marzo 2 de 2015. Visita

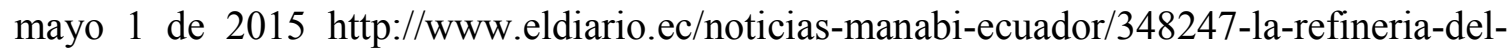
pacifico-tiene-un-12-de-avance/

E1 Diario (2014). "Les preocupa la maricultura". Mayo 14 de 2013. Visita mayo 1 de 2015 http://www.eldiario.ec/noticias-manabi-ecuador/264474-les-preocupa-la-maricultura/

El Telégrafo (2015). Zonas de desarrollo crearán más de 4.000 empleos. Diciembre 2 de 2013. Sección Economía. En: http://www.telegrafo.com.ec/economia/item/zonas-dedesarrollo-crearan-mas-de-4-000-empleos.html

El Telégrafo (2014). "El sector florícola genera 103 mil fuentes de trabajo". Sección Economía. Junio 11 de 2014. Visita mayo 1 de 2015 http://www.telegrafo.com.ec/economia/item/el-sector-floricola-genera-103-mil-fuentes-deempleo.html

El Telégrafo (2014). "Visita a Catar abrió puentes de inversión en sectores petrolero, turístico y agroindustrial". Sección Política, octubre 28 de 2014. Visita mayo 1 de 2015 http://www.telegrafo.com.ec/politica/item/visita-a-catar-abrio-puentes-de-inversion-ensectores-petrolero-turistico-y-agroindustrial-galeria.html

El Telégrafo (2013). "Caña de azúcar propicia cambio de matriz energética del país". Sección Economía, octubre 06 de 2013. Visita mayo 1 de 2015 http://www.telegrafo.com.ec/economia/item/cana-de-azucar-propicia-cambio-de-matrizenergetica-del-pais.html

El Telégrafo (2013). "El biocombustible ahorra 14 millones de dólares al Estado". Diciembre 15 de 2013. Visita mayo 1 de 2015

http://www.telegrafo.com.ec/economia/item/el-biocombustible-ahorra-14-millones-dedolares-al-estado.html

El Universo (2015). "Camaronera pasó a grupo de cangrejeros en el golfo". Abril 22 de 2015. Visita 2015 http://www.eluniverso.com/noticias/2015/04/22/nota/4795646/camaronera-paso-grupocangrejeros-golfo 


\section{Entrevistas:}

Sr. Líder Góngora y Sra. Marianelli Torrez, Coordinadora C-CONDEM, Julio 3 de 2015.

Sra. Consuelo Mosquera, Presidenta asociación Buen Vivir, Junio 1 de 2015.

Ing. Yahira Piedrahita, Directora Ejecutiva, Cámara Nacional de Acuacultura, Junio 1 de 2015.

Recebido em 21/07/2015.

Aceito para publicação em 05/04/2016. 